\title{
Project of Information Entering the Villages and Households: A Powerful Booster for China's Agricultural Information Construction Under the Background of Rural Revitalization
}

\author{
Ma Guojun \\ Jiangxi Normal University, Nanchang, Jiangxi, 330022 \\ mgj1527623503@163.com
}

Keywords: Project of information entering the villages and households (PIEVH), Informatization, Rural, Village-level information service station.

\begin{abstract}
The project of information entering the villages and households (This paper is referred to as PIEVH for short) is a basic project of agricultural informatization construction in China. With the rapid development of global economic informatization and digitization, the needs of modern agricultural information construction in rural areas are becoming more and more urgent. China's rural informatization started late, and many factors such as information culture environment, information resource integration and continuous operation mechanism restrict the development of rural informatization. Without informatization, there will be no modernization. The tilt of information resources and the extension of digital services for rural areas will play an important role in narrowing the digital divide between urban and rural areas and promoting the integration of urban and rural areas. In the current wave of China's comprehensive promotion of rural revitalization strategy, industrial prosperity is the premise for solving all rural problems, and is an important basis for rural revitalization. The continuous advancement of the PIEVH will help to form rural characteristic industries. Let the industrial products go down, the agricultural products go up, really benefit the countryside, promote the rural economic development, and realize the great strategy of rural revitalization.
\end{abstract}

\section{Introduction}

The elimination of rural poverty has always been a primary focus in China, since the development of rural areas affects the development of the entire country. As a big agricultural country, China has long been faced many problems such as the slow development of rural informatization and the imbalance of urban and rural economic development. The report of the 19th National Congress of the Communist Party of China mentioned that the most difficult and arduous task for achieving the goal of building a well-off society in 2020 is in rural areas, especially in poverty-stricken areas. At present, the economic base of China's rural areas is relatively weak compared with urban areas, social resources are relatively scarce, information network equipment coverage is low, and agricultural information construction faces certain obstacles, especially in some remote and impoverished mountainous areas, the entry and extension of information resources are facing many challenges.

In order to speed up the improvement of the agricultural information service system, promote the development of urban and rural integration, meet the information needs of the peasant masses and the new agricultural management entities effectively, in May 2014, the Ministry of Agriculture of China requested that the information into the villages households project(PIEVH) should be carried out actively, and coordinate the agricultural public welfare service resources and rural areas. Socialize service resources, establish village-level information service stations, and let the agricultural and rural economy catch up with information-based express trains. In June 2019, the State Council issued the "Guiding Opinions on Promoting the Revitalization of Rural Industries", emphasizing the importance of promoting the entry of the PIEVH to the rural economic development and the overall revitalization of the countryside. By the end of 2018, 272,000 grassroots information service agencies had been built nationwide, with a total of 786,000 
person-times of village-level information workers, 95.79 million public welfare services for farmers and new agricultural business entities, and 314 million person-times of convenience services. The business transaction volume was 24.4 billion yuan.

\section{The status and function of the PIEVH.}

\subsection{Village-level information service station is an important carrier for the PIEVH.}

The PIEVH is an important project to speed up the construction of agricultural modernization and promote the increase of farmers' income. Among them, the construction of village-level information service station is the main content of the project. The village-level information service station adopts a market-oriented approach and provides four major services: public service, convenience service, e-commerce and training experience through the three-in-one operation mode of "government + operator + service provider" to achieve accurate information and services. Facilitate the village, with the goal of building a comprehensive information service platform for rural areas, and gradually improve the informatization of rural life information and agricultural production. Since introducing PIVEH, the results have been remarkable since the beginning of the project. At the end of 2019, the number of village-level information service stations will cover more than $80 \%$ of the administrative villages nationwide. By the end of 2020, we plan to achieve the goal of covering all administrative villages with village-level information service stations.

Village-level information service stations are divided into standard stations, simple stations, professional stations and central stations according to the content and scope of services provided. The standard station relies on the construction of administrative villages, and selects areas with convenient transportation, dense farmers and large populations to ensure comprehensive coverage of the four major types of services and provide one-stop services. The simple station relies on the construction of various rural commercial outlets, such as agricultural materials stores, veterinary drug feed stores, convenience supermarkets, providing agricultural production materials, consumer goods purchase and e-commerce services. The professional station relies on the construction of new agricultural business entities such as family farms, large professional households, farmer cooperatives, and leading enterprises in agricultural industrialization. It mainly focuses on agricultural professional services and provides services to members around agricultural production and business activities. On the basis of the basic construction of the village-level station system, it is encouraged to build county-level and necessary township-level central stations. In addition to the basic functions of the standard station, the central station also undertakes the management and guidance of the village-level stations in the region, the sharing of resources, and the distribution of logistics, etc., to promote the cooperation and interconnection of the village-level stations in the region.

Table 1. Different types of village-level information service stations

\begin{tabular}{cl}
\hline Types & \multicolumn{1}{c}{ Construction organization } \\
\hline Central station & $\begin{array}{l}\text { Town agricultural department and third-party } \\
\text { management agency }\end{array}$ \\
\hline Professional station & $\begin{array}{l}\text { Agricultural cooperatives, large professional } \\
\text { households, agricultural enterprises and other new } \\
\text { agricultural business entities }\end{array}$ \\
\hline Standard station & $\begin{array}{l}\text { Family farms, large professional households, } \\
\text { farmer cooperatives, agricultural enterprises and } \\
\text { other new agricultural business entities or service } \\
\text { entities. }\end{array}$ \\
\hline Simple station & $\begin{array}{l}\text { Such as agricultural materials stores, } \\
\text { telecommunications service outlets, veterinary } \\
\text { drug feed stores, convenience supermarkets, } \\
\text { canteens, etc. }\end{array}$ \\
\hline
\end{tabular}




\subsection{The role of the PIEVH in promoting agricultural modernization.}

The Internet-centered information technology has affected people's production and life extensively and profoundly. Informatization has also penetrated into all aspects of rural construction and development. Under the background of the full implementation of the rural revitalization strategy, the PIEVH can play an important role in promoting China's agricultural modernization.

First of all, as the basic service unit of the "last mile" of rural informatization, it plays an irreplaceable role in stimulating the vitality of rural economy and integrating rural economic factors. Not only can provide farmers with agricultural policy consultation, agricultural skills teaching, weather release and other public services, but also provide premium recharge, express delivery Inquiries, hospital registration, aiding farmers' withdrawals, and other convenience businesses, integrating information services with farmers' lives, is conducive to meeting the growing information needs of farmers.

Secondly, the PIEVH can promote the revitalization of rural industries. By driving the transformation of agricultural production mode through agricultural informatization, information can play a guiding role in agricultural production, agricultural Internet of Things can improve the allocation efficiency of production factors, e-commerce can expand agricultural product sales channels and reduce circulation costs, and drive down the quality of industrial products. The entry of the village and the characteristic agricultural products into the city will form a two-way interactive circulation pattern between the rural and the urban areas, stimulate the potential vitality of the market, and achieve the precise connection between consumer demand and production supply.

Finally, the PIEVH can lead the flow of talent through information flow, which is conducive to cultivating new farmers with culture, technology and management, expanding the space for employment and entrepreneurship, and providing good environmental conditions for mass entrepreneurship and innovation. At the same time, some people will be sent back to work to solve certain employment problems.

\section{Problems with the PIEVH.}

Since the launch of the PIEVH, the project has achieved remarkable results in terms of construction scale and construction speed, and has also brought considerable benefits in actual operations. Overall the construction of the project made good progress, but still existed some problems to be improved urgently.

\subsection{Active rural information and cultural environment has not yet formed.}

China's informatization development started late, rural areas have long been in a closed or semi-closed state of lack of information introduction, and information and cultural environment construction is scarce. However, with the explosive development of Internet technology in recent years, China's informatization has developed rapidly and started. The continuous transmission of information resources to the rural areas has led to problems in rural areas that are incompatible with the demand for information services and supply due to the long-term lag in information development.

Farmers' modern information awareness is weak, they lack independent innovation of modern market economy consciousness, avoid new things or new wave of thought, avoid new things or the new wave of ideas, can not keep up with the requirements of the information age, it is difficult to create a positive and healthy information culture environment, this impact in China The trend of rural population aging will be even more profound. In addition, the local agricultural sector pays less attention to the promotion of the PIEVH, is less motivated, and lacks the enthusiasm of actively investing in construction. 


\subsection{Rural infrastructure construction needs to be strengthened.}

The PIEVH has been continuously promoted. The coverage of village-level information service stations in rural areas is relatively weak. The investment in the Internet and new information technology needs to be strengthened, especially in some remote and backward poverty-stricken areas. Short-term infrastructure, low information access capacity, it is difficult to meet the information service needs, agricultural information is not fully and effectively received by the majority of farmers. Due to the lack of solid infrastructure support, the extension of the PIEVH to the backward areas has been hindered. Considering difficulties such as poor public utilities and remote locations and the rural revitalization strategy, information and communication infrastructure will remain an important policy focus in the future. Taking into account the difficulties of public facilities and remote areas and the rural revitalization strategy, the information and communication foundation Facilities will remain an important policy priority for the future.

At present, rural information resources are scattered and lack of centralized integration, resulting in repeated decentralized resources and low utilization rates. The PIEVH provides a wide range of services, the content covers a wide range, but the integration is not enough, and some services have not been effectively used, the service suitability of different services in different regions, information services are uneven, updated The problem is slow, and problems difficult to adapt to local production conditions and actual conditions still exist.

\subsection{Lack of strong momentum in continuous operations.}

The PIEVH has been in the village for many years. The lack of long-term effective sustainable development is one of the most prominent problems it faces. It is the bottleneck of the development of the PIEVH and affected by many aspects.

For the construction of village-level information service stations, regardless of the pre- or post-operation, the investment in funds is insufficient. When the village-level information service station is initially listed, the government will provide certain construction funds. Afterwards, it will be market-oriented, and the government will not give a lot of financial support. The village-level information service station mainly provides public welfare services and lacks profit points. The financing channels are not wide enough, and sustainable development funds are difficult to guarantee. In addition, the lack of clear interest relationships among the various entities, the inconsistency of interests between the subjects, the comprehensive ability of the information workers and the willingness to perform functions are also reasons why the village-level information service stations are difficult to continue to operate.

\section{Countermeasures}

\subsection{Leading top-level design and strengthening publicity.}

The agricultural departments at all levels must recognize the importance of the PIEVH to the rural informatization development, base on the actual needs of farmers, lead the top-level design, form a clear and specific promotion mechanism, improve relevant policies and regulations, and establish appropriate incentive mechanisms. The construction of village-level information service stations can not only stay at the level of encouragement and support of the higher-level agricultural departments, but must be implemented from the top to the bottom, and the municipal, county, and village grassroots departments should implement relevant policies and implement them in light of local actual conditions. Promote construction. We will increase publicity and education in various aspects, improve the information literacy of the public through demonstration, guidance, education, etc., and mobilize all sectors of the society to take part in it. Through news reports, exhibitions and other initiatives, we will establish a sense of service and strive to create a good The rural information development environment and the development of quality rural information services. 


\subsection{Accelerate infrastructure construction and integrate information resources.}

Further strengthen the construction of rural informatization service infrastructure, speed up the popularization of Internet in rural areas, expand the spread of resources such as cable television, mobile communications, and broadcasting, improve the utilization of information resources and the quality of information services. Advance to provide good software and hardware facilities. Integrate agriculture-related resources, build on city-level agricultural big data centers based on local agriculture-related information platforms, and use information technologies such as the Internet, cloud computing, and big data to realize collaborative sharing of various types of data across industries and departments. A socialized shared service platform that satisfies agricultural research, management, and promotion of production needs to improve the data collection and information resource release functions of village-level information service stations.

\subsection{Focus on innovation and establish a continuous operation mechanism.}

In order to solve the bottleneck problem of the PIEVH, it is necessary to give play to the sense of innovation and build a long-term operational mechanism, which can be considered from the following aspects.

First, increase capital investment. Government departments should appropriately adjust the proportion of fiscal expenditures, increase capital investment, build rural information service infrastructure, and provide certain financial guarantees for the follow-up operations of village-level information service stations.

Second, the innovative operating mechanism. The village-level information service station operates under the three-in-one mechanism of "government + operator + service provider", ignoring the status that the important subject of farmers should not be neglected in the promotion of information into the village and even in the development of rural informatization. The construction of the PIEVH should clarify the main position of the peasants, and be dominated by the market, attract social resources, carry out market-oriented operations. At the same time, strengthen the interests of farmers, governments, operators and service providers, and form a common coordination. The operational mechanism of development.

Third, attach importance to personnel training. The construction of rural informatization is inseparable from professional talents. It is necessary to fully tap and introduce excellent talents, strengthen the training of relevant personnel, improve the talent management system, and provide fresh blood for the development of rural informatization in China.

\section{The conclusion}

Agricultural informatization is becoming an important way to develop modern agriculture, and it plays an increasingly important role in our production and life. As a project to help farmers and farmers, information-based households use information technology to enable farmers to carry out daily life and production more efficiently and conveniently, and to realize the effective transmission of information resources to rural areas, which will help improve rural areas. The regional modern network system, bridging the digital divide between urban and rural areas, and opening up the "last mile" of information high-speed, so that farmers can truly enjoy the dividends brought about by the development of economic informatization, it is a powerful booster for realizing the great strategy of rural revitalization.

\section{References}

[1] Xiaoqian Zhang, Feng Yang. Rural informatization policy evolution in China: a bibliometric study[J]. Scientometrics, 2019, Vol.120 (1), pp.129-153.

[2] Wang Bing, Tao Zhongliang, Zhu Ying. Content analysis and application practice of different types of information service station[J]. Journal of Zhejiang Agricultural Sciences, 2019, 60 (05): 835-839. 
[3] Zhou Xiaoxun, Xiong Chunlin. Promoting Impact of Rural Basic Information Service Station on the Rural Economic Development[J]. Journal of Central South University of Forestry and Technology (Social Science Edition), 2015, 9 (03): 85-88.

[4] Liu Jifang, Wu Jianzhai, Zhang Jianhua, Kong Fantao. Progress and Countermeasure about the Project of Information Entering into Villages and Households - Based on the Research Report of Henan and Guizhou Provinces[J]. Agricultural Outlook, 2018, 14(10): 63- 67.

[5] Huang He, Zhu Deqiong. An Empirical Study of Rural Information Service in the Era of Big Data_-Based on the Investigation of Guiyang City[J]. Journal of Guizhou Normal University (Social Science Edition), 2016(04): 52-63.

[6] Feng Xian, Li Wei, Guo Meirong. Rural Information Services Mode Innovation and Service Effective Evaluation under the"Internet connect"in China[J].Document, Information \& Knowledge, 2016(06): 4-15. 